\title{
AWARENESS ABOUT PULMONARY TUBERCULOSIS IN PEOPLE FROM HILLY REGION OF UTTARAKHAND
}

Deependra Kumar Rai ${ }^{1}$, Shyama ${ }^{2}$

\section{HOW TO CITE THIS ARTICLE:}

Deependra Kumar Rai, Shyama. "Awareness about Pulmonary Tuberculosis in People from Hilly Region of Uttarakhand". Journal of Evolution of Medical and Dental Sciences 2015; Vol. 4, Issue 46, June 08;

Page: 7878-7886, DOI: $10.14260 /$ jemds/2015/1149

ABSTRACT: BACKGROUND: India has the highest burden of Tuberculosis (TB) in the world, accounting for approximately one fifth of the global incidence. TB is a classical example of a disease with both medical and social dimensions, characterized by its close relation to poor socio-economic conditions. There are many studies has been conducted about awareness about tuberculosis in different part of country. But there are no studies about tuberculosis awareness in peoples from Garhwal region of Uttrakhand which may be due to different geographical location. MATERIAL \& METHODS: This was hospital based cross-sectional observational studies conducted in Government medical college Srinagar, Garhwal Uttarakhand. The study was conducted among 251 patients. Patients were interviewed at chest OPD by medical social worker with pretested Performa constituted of oral questionnaire in Hindi containing socio-demographic variable such as age, sex, religion, literacy status, and knowledge about symptoms, investigation, and treatment of tuberculosis. RESULTS: Cough is the commonest symptom rightly pointed by $77.29 \%$ patients. Sputum sample used for diagnosis of PTB known by $54.98 \%$. TB is a curable disease told by $62.54 \%$ patients but $54.98 \%$ patient's belief that it could be cured by non-medical treatment. As many as $45.01 \%$ patients heard the word DOTS but more than that $48.20 \%$ patients thought treatment require hospitalisation. Majority believe that private medicine is more effective. Only $30.26 \%$ patients were aware that tuberculosis treatment requires 6-8 months of treatment. Awareness about tuberculosis among tuberculosis patients was not significantly different $(\mathrm{p}>0.05)$ compared to non-tuberculosis patients. CONCLUSION: There is need to give more emphasis on health education about tuberculosis in remote places like hilly areas of Uttarakhand.

KEYWORDS: Tuberculosis (TB), directly observed treatment short course chemotherapy (DOTS), Awareness.

INTRODUCTION: India has the highest burden of Tuberculosis in the world, accounting for approximately one fifth of the global incidence. An estimated 2.3 million cases occur annually, of which 0.8 million are sputum-smear positive. ${ }^{1}$ Everyday in India more than 20,000 people develop the disease, and more than 1000 die from Tuberculosis (TB). TB is a classical example of a disease with both medical and social dimensions, characterized by its close relation to poor socio-economic conditions. ${ }^{2}$ To achieve goals of revised national tuberculosis control programme requires active community participation by way of creating awareness about aetiology, clinical presentation, treatment, preventive measures, and information of availability of services, etc., for TB. Patients' adherence to the treatment depends on many psychological and sociological factors including age, education level and patient's own idea about the disease. ${ }^{3}$ It is also essential to disseminate information and interact with the people for removing fear and stigma associated with TB so that people can come forward for seeking care. 
Indian population is composed of people of diverse cultural, linguistic, biological, ethnic and genetic backgrounds, living in different socio-cultural and socio-economic settings. There are many studies has been conducted about awareness about tuberculosis in different part of country. But there are no studies about tuberculosis awareness in peoples from Garhwal region of Uttrakhand which may be due to different geographical location.

The basic purpose of this study to measure awareness about tuberculosis in patients from Garhwal region of Uttarakhand.

\section{OBJECTIVES:}

Primary Objectives: To assess current awareness about pulmonary tuberculosis regarding symptoms, diagnosis, DOTS \& treatment in patients coming tertiary care hospital of Garhwal, Uttarakhand.

Secondary Objectives: To assess differences in awareness about pulmonary tuberculosis in literate versus Illiterate, gender differences and patients who have had treated with tuberculosis.

MATERIALS \& METHODS: This was a hospital based cross-sectional study conducted in a tertiary care teaching hospital situated in sub Himalayan zone of Uttarakhand. This hospital caters health need of a large geographical area of hilly region. After approval from Institutes ethical committees the study was conducted between $1^{\text {st }}$ December 2012 to 31 ${ }^{\text {st }}$ January 2013. During study period total 729 patients visited in Chest outpatient department. Applying Taro Yamini formula for estimating sample size in case of hospital based study; the sample size was estimated to be around 248 at $5 \%$ level of significance. The study was conducted among all 251 patients. All patients coming on Monday, Wednesday and Friday are included in study. Patients were interviewed at chest OPD by medical social worker with pretested Performa constituted of oral questionnaire in Hindi containing sociodemographic variable such as age, sex, religion, literacy status, and knowledge about symptoms, investigation, and treatment of tuberculosis. A Questionnaire with total of 10 questions was developed by department of Pulmonary Medicine after discussion with faculties from Community Medicine for validation. Among 10 questions 4 questions have multiple choices and six questions had two choices in form of yes or no. The option YES was selected as right answer except in three question (TB treatment require hospitalisation, TB can be cured by other than medical treatment and Government supply drug is less effective than private medicine) in questionnaire in which choice of NO had been taken as right answer. Each interview lasted for about 30 minutes.

DATA ANALYSIS: The collected data was entered in Microsoft Excel and transformed to SPSS statistical package for suitable statistical analysis and inferences were drawn. Z-test for difference between two proportions was applied for statistical significance.

RESULT: We had interviewed 251 patients irrespective of diseases coming to chest OPD. Patients were interviewed at chest OPD by medical social worker with pretested Performa constituted of oral questionnaire in Hindi containing socio-demographic variable such as age, sex, religion, literacy status, and knowledge about symptoms, investigation, and treatment of tuberculosis. Out of these 251 patients, 157(62.54\%) were male and 94(37.45) were female. General Characteristics of the studied patients had similar distribution in rural and urban areas. Chi- square test was used to measure independence of association. Majority of the patients 192(76.49\%) belonged to rural area 


\section{ORIGINAL ARTICLE}

while rest $59(37.45 \%)$ were from urban region. As far as literacy status was concerned, 71 patients (28.28\%) were illiterate. (Table 1)

Cough as the commonest symptom was rightly pointed by 194 (77.29\%) patients while cough of more than 2 weeks as tuberculosis suspect was correctly said by only 66(26.29\%) patients. Majority of the patients $114(54.98 \%)$ responded correctly as sputum sample used for diagnosis of tuberculosis. Tuberculosis is a curable disease told by $157(62.54 \%)$ patients but $138(54.98 \%)$ patients responded as tuberculosis can be cured by other medical than medical like indigenous treatment. Similar number of patients 138(54.98\%) aware that anti-tubercular drug being given free of cost by government. As many as 113(45.01\%) patients had heard the word DOTS but more than that $121(48.20 \%)$ patients thought that treatment of tuberculosis requires hospitalization. About $133(45.01 \%)$ patients believed that Government supply drug is less effective than private medication. Only 76(30.26\%) patients were aware that tuberculosis treatment requires 6-8 months of treatment. (Table 2)

As far as literacy status was concerned, literate were more aware about cough as the most common symptom of tuberculosis (82.22\% vs. 64.78\%), cough with 2-3weeks duration as tuberculosis suspect (31.66\% vs. $12.67 \%$ ), sputum is used for diagnosis (48.88\% vs. $36.61 \%$ ), heard the word DOTS (55.55\% vs. 18.31\%), Anti Tubercular drugs freely available (73.88\% vs. 35.22\%), tuberculosis is a curable diseases (68.88\% vs. $46.47 \%)$, tuberculosis treatment requires 6-8 month of treatment (37.77\% vs. $11.26 \%$ ), treatment requires hospitalization (51.66\% vs. $39.43 \%)$ than illiterate patients. Literate and illiterate patients were similar in opinion $(55.82 \%$ vs. $53.52 \%)$ regarding government supply drug is less effective than privately available medicine. Illiterates were more believing that tuberculosis treatment requires hospitalization (64.71\% versus $51.11 \%)$. Overall awareness about pulmonary tuberculosis was significantly higher among literate patients as compared to illiterate patients with respect to almost all variable except sputum as diagnostic test for tuberculosis $(\mathrm{p}=0.07)$, treatment require hospitalization $(\mathrm{p}=0.08)$ and DOTS treatment is less effective than private medicine. (Table 3).

If we compare awareness among gender, males were more aware about tuberculosis such as cough is most common symptom, heard DOTS name, tuberculosis is a curable diseases, treatment require 6-8 month, treatment require hospitalisation than female patients. Female patients' outnumbered male patients in awareness such as tuberculosis treatment require hospitalisation and government supply anti TB medicine are less effective than private medicine. So males had significantly better awareness about tuberculosis compared to female respect to all variable $(\mathrm{p}<0.05)$ (Table 4).

Patients who were on treatment or those who received anti TB drug in past were more aware about tuberculosis in questionnaire like sputum is most commonly used sample for diagnosis, heard DOTS, treatment require 6-8 month of treatment, tuberculosis treatment id freely available. Patients who never received anti TB drugs believed that government supply medicine is less effective and tuberculosis can be cured by other than medical treatment. Awareness about tuberculosis among tuberculosis patients was not significantly different ( $p>0.05$ ) compared to non-tuberculosis patients. (Table 5)

Cough is the most common symptoms of tuberculosis pointed out by $77.29 \%$ patients while some patients responded as only fever or only cough in $11.55 \%$ or $7.17 \%$ respectively and rest of patients don't know any symptoms about pulmonary tuberculosis. The treatment duration of 6-8 months which was right option rightly responded by $30.27 \%$ patients. The remaining patients 


\section{ORIGINAL ARTICLE}

responded as 2-3 months, $10-12$ month and some patients don't have idea in $23.90 \%, 8.36 \%$ and $37.45 \%$ respectively.

DISCUSSION: This study revealed much important information about awareness about tuberculosis in people from hilly region of Uttarakhand. The awareness about tuberculosis symptoms varies in different parts of country. In the present study, patient were aware that cough with sputum is the most common (77.29\%) symptom followed by Fever (11.55\%), and haemoptysis $(7.17 \%)$ and rest (4.13\%) patients doesn't aware of any symptoms. On contrary study conducted on patient attending the DOTS Center at Safdarjung Hospital New Delhi, fever (50.6\%), cough (59.3\%), weight loss (20.6\%), expectoration (11.3\%), haemoptysis (11.3\%) were reported to be the main symptoms of tuberculosis, known to the people. ${ }^{4}$ In a study conducted in south Indian rural population, cough, fever and haemoptysis were known to $66 \%, 13 \%$ and $15 \%$ of the individual respectively. ${ }^{5}$ In another study conducted in rural population of Delhi, it was found that cough and sputum (73.7\%), weakness and breathlessness (40.4\%), fever (34.3\%) and haemoptysis were known to be the symptom of tuberculosis among the people. ${ }^{6}$ If we analyse the investigation to be carried out for diagnosis of tuberculosis, $45.51 \%$ stated sputum examination and $25.89 \%$ stated X-ray while $17.52 \%$ stated blood and rest $11.15 \%$ patients doesn't aware. However in contrast to our findings, in a study conducted at DOTS Centre, Safdarjung Hospital, New Delhi, 62.6\% of the patients aware of that for diagnosis of tuberculosis sputum examination was the most preferred test followed by X-ray. ${ }^{4}$

Revised national control programme aggressively advertise that any person with cough of more than 3 weeks may have tuberculosis. In this study $29.48 \%$ patients were not aware of duration of cough required to suspect pulmonary tuberculosis. Cough with at least 3 weeks as suspect rightly stated by $26.29 \%$ followed by 4 weeks in $23.50 \%$, and duration of 5 weeks in $20.71 \%$ patients. There are no studies in past among people that consider awareness about duration of cough for tuberculosis suspect. Regarding word DOTS $45.01 \%$ of patient heard the word. Government supply anti tubercular drug is less effective than private medicine stated by same number of patients (45.01\%). Majority of the patient (62.04\%) believed that tuberculosis is curable. The duration (6-9 month) was correctly known to only $30.27 \%$ of the patients and rest of patients $23.90 \%$ states $2-3$ month, $10-12$ month by $8.36 \%$. The $37.45 \%$ of patients were not aware about duration of treatment. Patients who was on treatment for tuberculosis or treated in past correctly known the duration of treatment as 6-8 month in $45.23 \%$ and $27.27 \%$ among non-tubercular patients.

In a study done at DOTS Centre Safdarjung Hospital, New Delhi, 53.3\% of the patient knew that the treatment for tuberculosis was to be taken for a span of 6-9 month. ${ }^{4}$ A study done in rural areas of Tamil Nadu showed that 15\% patients knew about the duration and treatment before starting a health education campaign in the area. ${ }^{5}$ Tuberculosis is a curable diseases stated only in $62.54 \%$ patients. The same percentage of patients believes that treatment of tuberculosis is free and tuberculosis can be treated by other than medical treatment. Literacy is key factor determining awareness ${ }^{7}$. Literate patients are more aware about tuberculosis than Illiterates. Government supply drug is less effective equally stated by illiterate \& literate. There is no much differences in awareness about tuberculosis in patients who treated in past to those who never received treatment. This reflects poor health education about tuberculosis during treatment of tuberculosis.

The differences in finding in our studies in compare to other studies may be due to different selection of participants, different geographical location. 
CONCLUSION: This study revealed that majority of patients were aware about symptoms of tuberculosis. Awareness about pulmonary tuberculosis was significantly higher among literate patients. Awareness about tuberculosis among tuberculosis patients was not significantly different compared to non-tuberculosis patients. There is need to give more emphasis on health education about tuberculosis under tuberculosis control programme in remote places like hilly areas of Uttarakhand.

\section{REFERENCES:}

1. World Health Organisation, Geneva (2011) WHO Report on Global Tuberculosis Control.

2. Jaggarrajamma K, Ramchandran R, Charles N, Chandrasekaran V, Muniuandi M and Ganapathy S. Psycho-social dysfunction: Perceived and enacted stigma among tuberculosis patients registered under RNTCP. Indian J Tuberc2008; 55: 179-87.

3. IBakke PS, Honoa $\mathrm{R}$ and Culsuik A. Educational level and obstructive lung disease, given smoking habits and occupationalairborne exposure: A Norwegian Community Study. Am. J. Epidemiol.; 1995, 141: p. 1080.

4. Matta S, Singh D, Bhalla S, Rasania S, Singh S and Sachdev TR. A study on knowledge and family attitude of patients regarding Pulmonary Tuberculosis attending the DOTS Center of Safdarjang Hospital, New Delhi. Indian J. Prev. Soc. Med. 2005; 36/1\&2: p. 16 - 20.

5. Subramaniam $\mathrm{T}$ et al. Knowledge of tuberculosis in a South Indian rural community, initially and after health education. Indian J. Tuberc; 1999, 46: p. 251 - 4.

6. Malhotra R et al. Awareness regarding tuberculosis in a rural population of Delhi. Indian J. of Com. Med; 2002, Vol. XXVI, No. 2: p. 62 - 68.

7. Kar $M$ and Logaraj $M$. Awareness, attitude and treatment seeking behavior regarding Tuberculosis in a rural area of Tamil Nadu. Indian J Tuberc 2010; 57: p. 226-229.

\begin{tabular}{|c|c|c|c|c|c|}
\hline Characteristic & $\begin{array}{c}\text { Rural }(n=192) \\
(76.49 \%)\end{array}$ & $\begin{array}{c}\text { Urban }(n=59) \\
(23.50 \%)\end{array}$ & $\begin{array}{c}\text { Total }(n=251) \\
(100 \%)\end{array}$ & $x^{2}$ & $P$ value at 1d.f \\
\hline $\begin{array}{c}\text { Sex } \\
M\end{array}$ & $121(63.02)$ & $36(61.01)$ & $157(62.54)$ & \multirow[t]{2}{*}{0.774} & \multirow{2}{*}{$\mathrm{P}=0.781$ at $1 \mathrm{~d} . \mathrm{f}$} \\
\hline $\mathrm{F}$ & 71(36.97) & $23(38.98)$ & $94(37.45)$ & & \\
\hline \multicolumn{6}{|l|}{ Education } \\
\hline Illiterate & $60(31.25)$ & $11(18.64)$ & $71(28.28)$ & \multirow{2}{*}{3.53} & \multirow{2}{*}{$\mathrm{P}=0.06$ at $1 \mathrm{~d} . \mathrm{f}$} \\
\hline Literate & $132(68.75)$ & $48(81.35)$ & $180(71.71)$ & & \\
\hline \multicolumn{6}{|l|}{ Employment } \\
\hline Unemployed & $98(51.04)$ & $33(55.93)$ & 131(52.19) & \multirow{2}{*}{0.7452} & \multirow{2}{*}{$\mathrm{P}=0.388 \mathrm{at} 1 \mathrm{~d} . \mathrm{f}$} \\
\hline Employed & $94(48.95)$ & $26(44.06)$ & $120(47.80)$ & & \\
\hline \multicolumn{6}{|l|}{ Category } \\
\hline General & $137(71.35)$ & $38(64.40)$ & $175(69.72)$ & \multirow{3}{*}{1.85} & \multirow{3}{*}{0.396 at 2 d.f } \\
\hline OBC & $13(6.77)$ & $7(11.86)$ & $22(8.77)$ & & \\
\hline $\mathrm{SC}+\mathrm{ST}$ & $42(21.87)$ & $14(23.27)$ & $54(21.51)$ & & \\
\hline
\end{tabular}




\begin{tabular}{|c|l|c|c|c|}
\hline \multicolumn{1}{|c|}{ Characteristics } & Yes & No & $\begin{array}{c}\text { Positive } \\
\text { response \% }\end{array}$ \\
\hline 1. & TB symptoms as cough & 194 & 57 & 77.29 \\
\hline 2. & $\begin{array}{l}\text { Cough with at least 3wks. duration suspect for } \\
\text { TB }\end{array}$ & 66 & 186 & 26.29 \\
\hline 3. & Sputum sample for diagnosis & 114 & 137 & 45.51 \\
\hline 4. & Have you ever heard name DOTS & 113 & 138 & 45.01 \\
\hline 5. & PTB Treatment 6-8 month & 76 & 175 & 30.27 \\
\hline 6. & TB treatment is free & 138 & 113 & 54.98 \\
\hline 7. & Treatment require hospitalisation & 121 & 130 & 48.20 \\
\hline 8. & Is it Curable & 157 & 94 & 62.54 \\
\hline 9. & TB can be cured by other than medical treatment & 138 & 113 & 54.98 \\
\hline 10. & $\begin{array}{l}\text { Govt supply drug (DOTS) less effective than } \\
\text { Private medicine }\end{array}$ & 133 & 118 & 45.01 \\
\hline
\end{tabular}

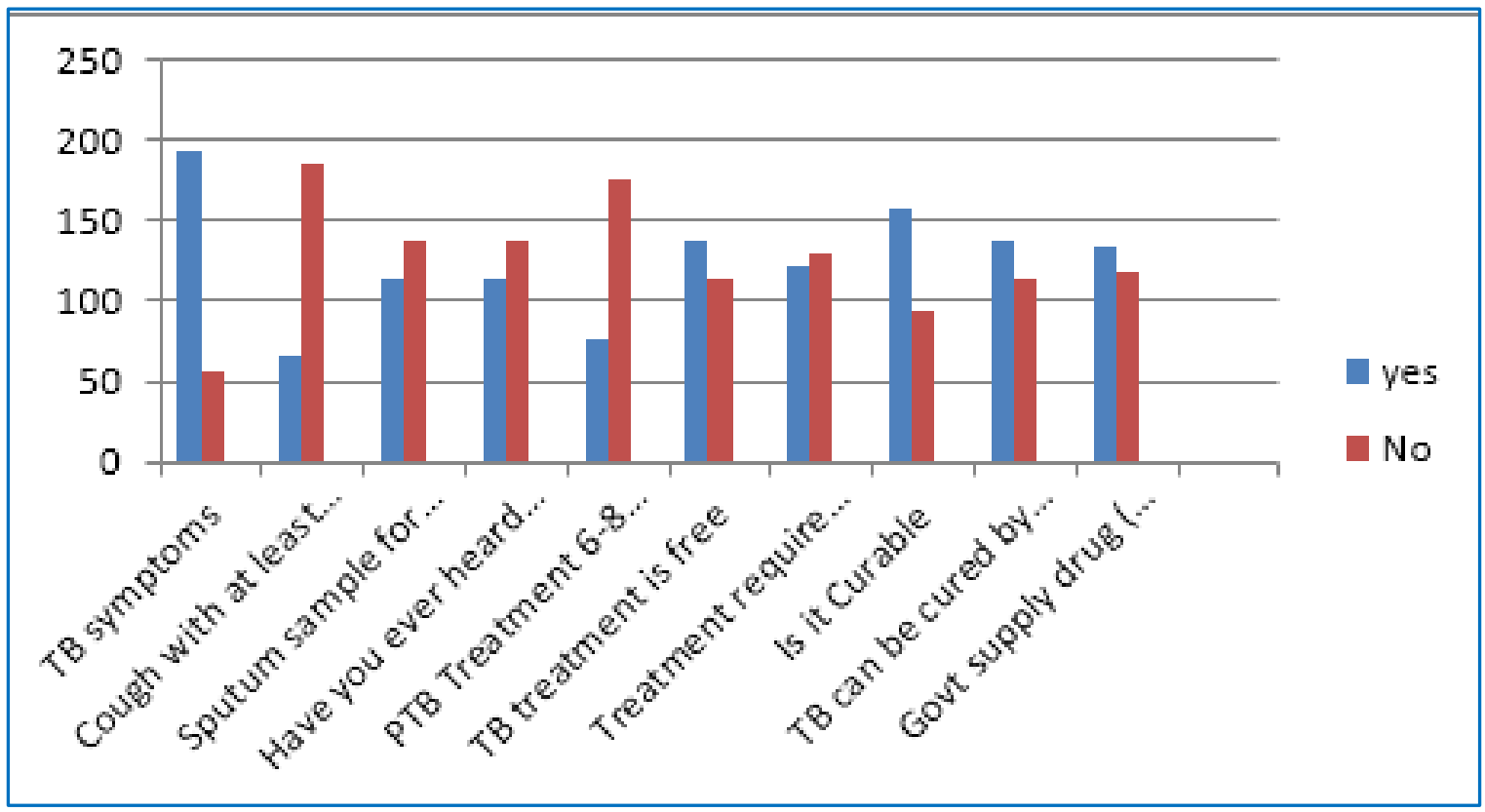

\section{Fig. 1: Awareness about tuberculosis}

Number on Y axis represent number of patients. 


\begin{tabular}{|c|c|c|c|c|c|}
\hline & & $\begin{array}{l}\text { Illiterate } \\
(n=71)\end{array}$ & $\begin{array}{l}\text { Literate } \\
(\mathrm{n}=180)\end{array}$ & Z -test & p value \\
\hline 1. & TB symptoms as cough & $46(64.78)$ & $148(82.22)$ & 2.96 & 0.003 \\
\hline 2. & $\begin{array}{l}\text { Cough with 2-3wks. } \\
\text { duration suspect for TB }\end{array}$ & $09(12.67)$ & $57(31.66)$ & 3.078 & 0.002 \\
\hline 3. & Sputum as diagnostic test & $26(36.61)$ & $88(48.88)$ & 1.75 & $\begin{array}{c}0.078 \\
\text { NS }\end{array}$ \\
\hline 4. & $\begin{array}{l}\text { Have you ever heard name } \\
\text { DOTS }\end{array}$ & $13(18.30)$ & $100(55.55)$ & 5.34 & 0.0001 \\
\hline 5. & PTB Treatment 6-8 month & $08(11.26)$ & $68(37.77)$ & 4.11 & 0.0001 \\
\hline 6. & TB treatment is free & $25(35.22)$ & 133(73.88) & 5.72 & 0.0001 \\
\hline 7. & $\begin{array}{l}\text { Treatment require } \\
\text { hospitalisation }\end{array}$ & $28(39.43)$ & $93(51.66)$ & 1.74 & $\begin{array}{c}0.08 \\
\text { NS }\end{array}$ \\
\hline 8. & Is it Curable & $33(46.47)$ & $124(68.88)$ & 3.30 & 0.001 \\
\hline 9. & $\begin{array}{l}\text { TB can be cured by other than } \\
\text { medical treatment }\end{array}$ & $46(64.78)$ & $92(51.11)$ & 1.9617 & 0.049 \\
\hline 10. & $\begin{array}{l}\text { Govt. supply drug (DOTS) less } \\
\text { effective than Private medicine }\end{array}$ & $38(53.52)$ & $97(53.88)$ & 0.05 & $\begin{array}{l}0.9580 \\
\text { NS }\end{array}$ \\
\hline
\end{tabular}

Values represent number of patients, Values in parenthesis represents \%.

\begin{tabular}{|c|c|c|c|c|c|}
\hline & & Male (157) & Female (94) & Z -test & p value \\
\hline 1. & TB symptoms as cough & $128(81.52)$ & $66(70.21)$ & 2.07 & $\begin{array}{l}0.038 \\
\text { NS }\end{array}$ \\
\hline 2. & $\begin{array}{l}\text { Cough with 2-3wks. } \\
\text { duration suspect for TB }\end{array}$ & $40(25.47)$ & $26(27.65)$ & 0.38 & $\begin{array}{l}0.70 \\
\text { NS }\end{array}$ \\
\hline 3. & $\begin{array}{l}\text { Sputum sample for } \\
\text { diagnosis }\end{array}$ & $76(48.40)$ & $38(40.25)$ & 1.22 & $\begin{array}{c}0.219 \\
\text { NS }\end{array}$ \\
\hline 4. & $\begin{array}{l}\text { Have you ever heard name } \\
\text { DOTS }\end{array}$ & $87(55.41)$ & $2(27.65)$ & 4.77 & 0.0001 \\
\hline 5. & PTB Treatment 6-8 month & $48(30.57)$ & $18(19.14)$ & 1.989 & 0.046 \\
\hline 6. & TB treatment is free & $90(57.32)$ & $48(51.06)$ & 0.96 & $\begin{array}{c}0.3346 \\
\text { NS }\end{array}$ \\
\hline 7. & $\begin{array}{l}\text { Treatment require } \\
\text { hospitalisation }\end{array}$ & $86(54.77)$ & $35(37.23)$ & 2.69 & 0.0071 \\
\hline 8. & Is it Curable & $112(71.33)$ & $45(47.87)$ & 3.71 & 0.0002 \\
\hline 9. & $\begin{array}{l}\text { TB can be cured by other } \\
\text { than medical treatment }\end{array}$ & $89(56.68)$ & $49(52.12)$ & 0.70 & $\begin{array}{c}0.482 \\
\text { NS }\end{array}$ \\
\hline 10. & $\begin{array}{l}\text { Govt. supply drug(DOTS) } \\
\text { less effective than Private } \\
\text { medicine }\end{array}$ & $92(58.59)$ & $42(44.68)$ & 2.139 & 0.03 \\
\hline
\end{tabular}

Values represent number of patients, values in parenthesis represents \%. 


\begin{tabular}{|c|l|c|c|c|c|}
\hline Sl. No & \multicolumn{1}{|c|}{ Characteristics } & $\begin{array}{c}\text { Old treated } \\
\text { PTB (n=42) }\end{array}$ & $\begin{array}{c}\text { Non TB patients } \\
(\mathbf{n = 2 0 9})\end{array}$ & Z- test & p value \\
\hline 1. & TB symptoms as cough & $31(73.80)$ & $163(77.99)$ & 0.59 & $0.55 \mathrm{NS}$ \\
\hline 2. & $\begin{array}{l}\text { Cough with 2-3wks. duration } \\
\text { suspect for TB }\end{array}$ & $13(30.95)$ & $53(25.35)$ & 0.75 & $0.45 \mathrm{NS}$ \\
\hline 3. & Sputum as diagnostic sample & $20(47.61)$ & $94(44.97)$ & 0.3139 & $0.75 \mathrm{NS}$ \\
\hline 4. & Have you ever heard name DOTS & $28(66.66)$ & $85(40.66)$ & 3.09 & 0.002 \\
\hline 5. & PTB Treatment 6-8 month & $19(45.23)$ & $57(27.27)$ & 2.31 & 0.021 \\
\hline 6. & TB treatment is free & $27(64.28)$ & $111(53.11)$ & 1.33 & $\begin{array}{c}0.184 \\
\mathrm{NS}\end{array}$ \\
\hline 7. & $\begin{array}{l}\text { Treatment require } \\
\text { hospitalisation }\end{array}$ & $25(59.52)$ & $96(45.93)$ & 1.61 & $0.11 \mathrm{NS}$ \\
\hline 8. & Is it Curable & $27(64.28)$ & $130(62.20)$ & 0.254 & 0.79 \\
\hline 9. & $\begin{array}{l}\text { TB can be cured by other than } \\
\text { medical treatment }\end{array}$ & $20(47.61)$ & $118(56.45)$ & 1.05 & 0.293 \\
& $\begin{array}{l}\text { Novt supply drug(DOTS) less } \\
\text { effective than Private medicine }\end{array}$ & $17(40.47)$ & $116(55.50)$ & 1.78 & 0.075 \\
& \multicolumn{2}{|r|}{ Table 5: Awareness about tuberculosis in patients with tuberculosis } \\
\hline
\end{tabular}

Values represent number of patients, values in parenthesis represents $\%$.

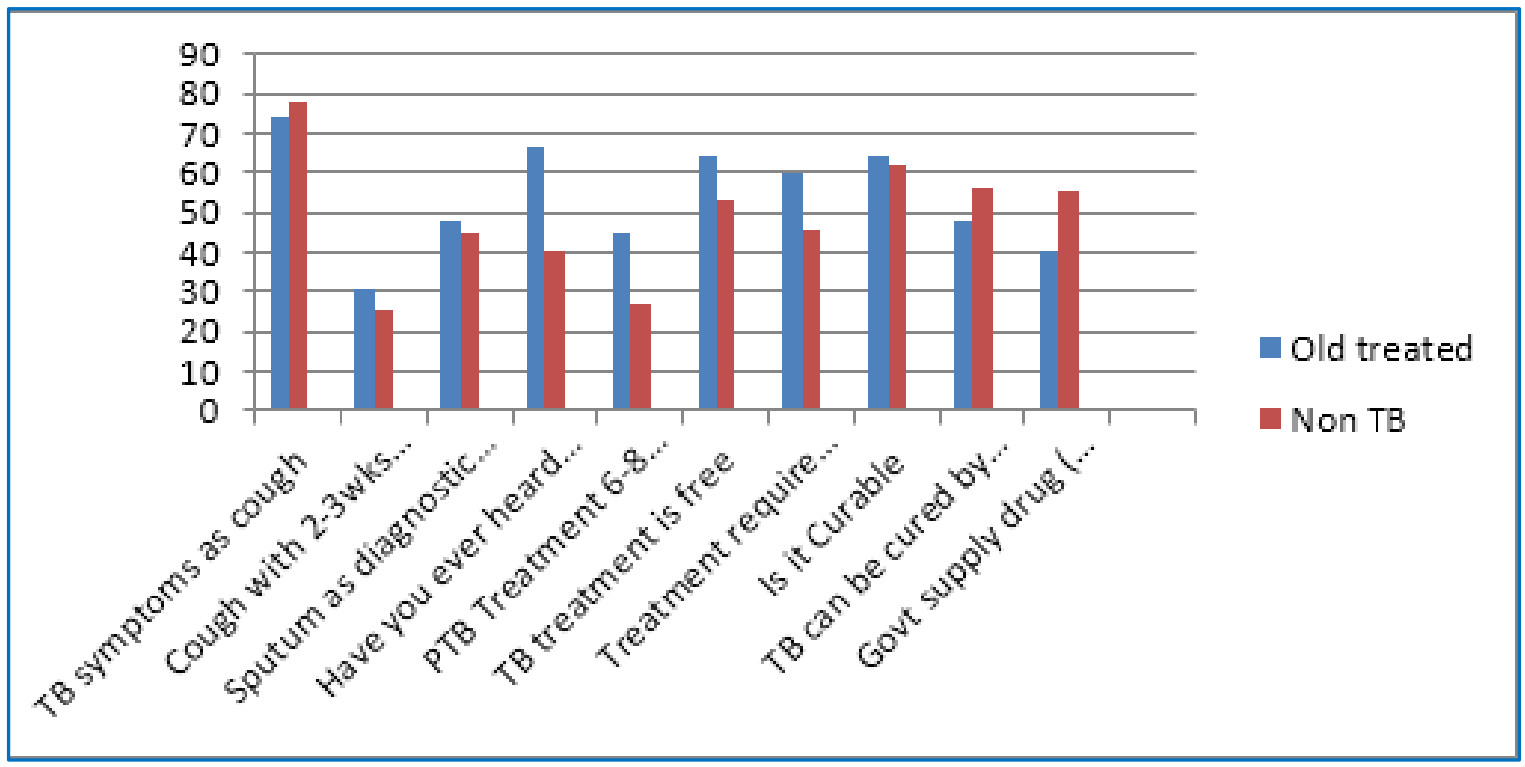

Fig. 2: Comparision of Awareness about Tuberculosis in Old treated to never treated pts

Number on Y axis represent percentage. 


\begin{tabular}{|c|c|c|}
\hline Symptoms & $\mathbf{n = 2 5 1}$ & Percentage (\%) \\
\hline Cough & 194 & 77.29 \\
\hline Fever & 29 & 11.55 \\
\hline Hemoptysis & 18 & 7.17 \\
\hline Don't know & 11 & 4.38 \\
\hline Treatment & & \\
\hline $2-3$ month & 60 & 23.90 \\
\hline 6-8 month & 76 & 30.27 \\
\hline 10-12 month & 21 & 8.36 \\
\hline Don't know & 94 & 37.45 \\
\hline Diagnosis & & \\
\hline Sputum & 114 & 45.41 \\
\hline CXR & 65 & 25.89 \\
\hline Blood & 44 & 17.52 \\
\hline Don't know & 28 & 11.15 \\
\hline TB suspect & & \\
\hline Cough with $>3 w k s$. & 66 & 26.29 \\
\hline$>4 w k s$. & 59 & 23.50 \\
\hline$>5$ wks. & 52 & 20.71 \\
\hline Don't know & 74 & 29.48 \\
\hline
\end{tabular}

Table 6. Comparative analysis of patients response regarding symptoms, diagnosis, and treatment

\section{AUTHORS:}

1. Deependra Kumar Rai

2. Shyama

\section{PARTICULARS OF CONTRIBUTORS:}

1. Assistant Professor \& HOD, Department of Pulmonary Medicine \& Tuberculosis, All India Institutes of Medical Sciences, Phulwarisharif, Patna.

2. Post Graduate Resident, Department of Kayachikitisha, Dayanand Ayurvedic College \& Hospital, Siwan.

\section{FINANCIAL OR OTHER} COMPETING INTERESTS: None

\section{NAME ADDRESS EMAIL ID OF THE} CORRESPONDING AUTHOR:

Dr. Deependra Kumar Rai, Assistant Professor \& HOD, Department of Pulmonary Medicine \& Tuberculosis, All India Institutes of Medical Sciences, Phulwarisharif-801505, Patna.

E-mail: deependra78@gmail.com

Date of Submission: 18/05/2015. Date of Peer Review: 19/05/2015. Date of Acceptance: 01/06/2015. Date of Publishing: 05/06/2015. 